ojed.org/jis

\title{
The Oxford Encyclopedia of Global Perspectives on Teacher Education
}

Jo Lampert (Ed.), Oxford University Press, 2019. 1568pp. ISBN-13 9780190670221

Reviewed by Yang Gao, Dalian Maritime University, China

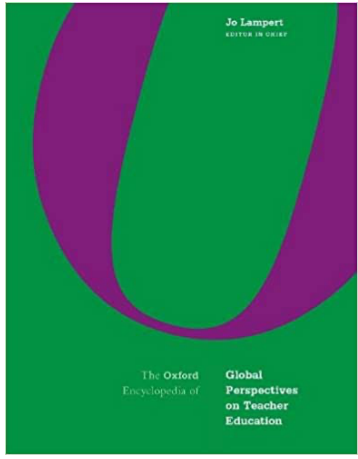

Jo Lampert, as the Editor-in-Chief, did a phenomenal job in collecting and editing works on teacher education for this book. I was hesitant to review the book at first, as I believed an encyclopedia (as the book title indicates) would require tons of effort to read and thus make the task challenging. However, having read the book, I am proud of myself as a reader who hasn't missed this contribution to the literature and even more proud of the authors who have contributed both classic and avant-garde works to the field. I would synthesize the book's benefits into two main categories: perspectives and availability. In terms of the perspectives, the book provides the reader with an assortment of views on teacher education; some are innovative and inspiring, some are combined and synthesized, and some are updated and newly developed from canonical works. As for availability, all collected works appear online as part of the Oxford Research Encyclopedia of Education, which makes access convenient.

As the book is not organized in chapters or sections, I frame this review through my classification of the perspectives. Specifically, my classification includes some paired, dichotomic perspectives with overlapping tenets. This review refers to exemplar articles from the book, rather than all contributions, given the abbreviated nature of a book review.

The first type of perspective is the dichotomy between theory-based and practice-based works. For example, some works focus on complexity theory (e.g., Martin et al.); postcolonial theory (e.g., Viruru \& Persky); disability critical race 
theory (e.g., Migliarini \& Annamma); and sociolinguistic theory, including systemic functional grammar (e.g., de Oliveria \& Smith) and translanguaging theory (e.g., Espana et al.), presenting how these theories are related to teacher education. Some of the theoretical frameworks may also relate to certain methodological, inquiry-based paradigms, including ethnographic inquiry (e.g., Rivas-Flores) and heuristic inquiry (e.g., Fogelgarn) in teacher education. Different from these theory-based contributions, several of the collected works are practice-based. For example, Cahnmann-Taylor and Sanders-Bustle offer an article on art-informed pedagogies in teacher preparation; Yang and MacLeod on blended-learning pedagogies; Gist et al. on culturally responsive pedagogy; and Hobbs et al. on trauma-informed pedagogy.

The second type of perspective is the dichotomy between canonical and emerging works. The encyclopedia includes quite a number of the former, some of which might be a revisiting or extended version of the existing literature. For example, Grenfell contributes an article guiding us to revisit Bourdieu and education, which offers lasting insight to teacher educators. Noddings' article on care in teacher education addresses how caring and being cared for are essential concepts in the field. Masny devotes an article to Deleuze and Guattari and teacher education but extends the line of inquiry with modes of thought to "problematize, conceptualize, and challenge normativity" (Masny, 2019, p. 1). On the other hand, some articles contribute to newly developed, innovative methods or consider how postmodernism has made contemporary teacher education different from previous versions. For example, there are quite a few articles discussing how the digitalized world has informed teacher education. Keengwe provides a chapter on globalization, digital technology, and teacher education in the United States; Kelly discusses how "networks make use of the capabilities of the internet and related technology to better support teachers" (p. 1). Additionally, Niess contributes a chapter on teachers' knowledge for the digital age.

The third type of perspective among the collected works is the dichotomy between indigenous and international perspectives. Some authors focus on indigenous teacher education, typically in developed, western countries. For example, Phillips pens a chapter on indigenous Australian studies with a proposal on how the indigenist standpoint pedagogical framework is inherently "reformative, relational, and critically reflexive" in supporting and facilitating students to re/intake indigenous knowledge (p. 1). There are also contributions in the collection that seek to broaden the scope of teacher education by using an international lens. For example, Panda contributes an article analyzing international standards and benchmarks among teacher training programs in different sample countries. Through the analysis, Panda recommends that standards and benchmarks should be flexible and dynamic.

One of the most important contributions that the book has made is the focus on "Global South" perspectives, which differ from previous publications in the field that typically stem from an American or European perspective. Specifically, the book includes myriad articles addressing the Asia Pacific region (e.g., Cheng; Forlin), including Japan (e.g., Nagashima) and Singapore (e.g., Chong \& Gopinathan; Loh \& $\mathrm{Hu}$ ). It also includes teacher education perspectives from 
Russia (Valeeca \& Kalimulin), Mexico (Hamann et al.), and South Africa (Soudien \& Sayed). All of these included perspectives make the book valuable indeed for the global reader.

Another type of perspective is the dichotomy between concept-orientation and stage-oriented articles. Specifically, a considerable number of core concepts or models have been (re)visited and extended through the collected works to probe their impacts on and relations with teacher education. These concepts include agency (Flessner \& Kandel-Cisco), reflection (Korthagen \& Nuijten), accountability (Mayer), teacher beliefs (Fives et al.; Tatto), teacher identity (Martínez-de-la-Hidalga \& Villardón-Gallego), teacher leadership (Frost), spiritual development (Mohanty), and well-being (Gustems-Carnicer \& Calderon). In addition, there are works focused on providing staging insights on teacher education. For example, some works highlight initial teacher education programs or teacher preparation programs (e.g., Sharplin et al.; Solomon; Zygmunt et al.), some teacher development (e.g., Jones \& Ellis; MadalińskaMichalak), and some teacher quality and assessment (e.g., Beck et al.; Deluca \& Braund; Polly).

While the book contributes to the field of teacher education with unique, innovative, and comprehensive perspectives, it might be even better if the editorial team had assembled clear-cut sections. The current format might cause the reader, especially one new to the field, to spend extra time in selecting their focal points. It is also worth mentioning that some of the collected works might be adapted versions (e.g., Burnett \& Lampert) or reprinted versions (e.g., Mayer; Mayer et al.) of previous, classic works (e.g., Lampert \& Burnett, 2016). In sum, this publication may serve as a stimulus to those interested in exploring the field of teacher education, as well as to those wanting to understand varied perspectives within teacher education.

\section{REFERENCES}

Kelly, N. (2019). Online networks in teacher education. In J. Lampert (Ed.), The Oxford Encyclopedia of Global Perspectives on Teacher Education. Oxford University Press. https://doi.org/10.1093/acrefore/9780190264093.013.416

Lampert, J., \& Burnett, B. (2016). Teacher education for high poverty schools (Vol. 2). Springer. https://doi.org/10.1007/978-3-319-22059-8

Masny, D. (2019). Deleuze and Guattari and teacher education. In J. Lampert (Ed.), The oxford encyclopedia of global perspectives on teacher education. Oxford University Press. https://doi.org/10.1093/acrefore/9780190264093.013.374

Phillips, J. (2019). Indigenous Australian Studies, indigenist standpoint pedagogy, and student resistance. In J. Lampert (Ed.), The Oxford Encyclopedia of global perspectives on teacher education. Oxford University Press. https://doi.org/10.1093/acrefore/9780190264093.013.257 
YANG GAO, $\mathrm{PhD}$, is an associate professor at Dalian Maritime University (DMU). Before his appointment at DMU, he taught at San Jose State University and Kent State University in the United States. Yang does research in TESOL and ESL teacher education. Email: gaoyang666@dlmu.edu.cn 